\title{
INTERNATIONAL FEDERATION OF ROBOTICS ACTIVITIES
}

A highlight of the International Symposia on Industrial Robots-to be renamed the International Symposia on Robots with effect from next year-is the recognition of people who have achieved distinction in robotics.

Three sets of awards were conferred during last year's 26th ISIR in Singapore.

The Engelberger Robotics Awards, offered by the US Robotic Industries Association for achievement in technology development, industry leadership and education, were presented during the symposium by $\mathrm{Mr}$ Engelberger himself (as is the custom). There were three recipients: Professor Takeo Kanade, director of the Robotics Institute of Carnegie Mellon University in the US, for his significant contributions in computer vision systems, mechanical systems, components and basic science; Mr Koh Kikuchi, president of Yaskawa Electric Corporation, Japan, for building that company into one of the world's largest robot manufacturers; and Professor Adam Morecki of Warsaw Univërsity of Technology, Poland, for his efforts in establishing robotics technology in that country.

The Golden Robot Award, sponsored by the Flexible Automation division of $\mathrm{ABB}$, was awarded to Mr Egon Olszewski, director of metal working in the German firm Benteler AG. Mr Olszwewski introduced robotic arc welding technology in his company, which now employs 700 robots in its factories in several countries. He told the 26th ISIR that even in countries with comparatively low wage costs, such as the Czech Republic, Mexico and People's Republic of China, investments in robots are required to meet market demands for quality products.

The Japan Robot Association conferred awards upon authors of the papers judged to have been best presented to the 25th ISIR in Hannover, Germany in 1994. An award in the area of research and development was given to Professor Shigeki Toyama and his colleagues in Tokyo Agriculture and Technology University and Omron Inc. for a paper entitled "Development of multi degree of freedom spherical ultrasonic motor". Another award in the area of application technology went to Professor Gerd Hirzinger and his colleagues in the German Aerospace Research Establishment DLR for their paper "Transferring space robot technologies into terrestrial applications".

This year's awards will be presented during the 27th ISIR which will take place in Milan from 6 to 8 October.

A principal activity of the International Federation of Robotics is the compilation of annual statistics of the world's robot population based upon inputs from IFR member associations round the world. This activity, carried out in close co-operation with the United Nations, results in an annual publication containing not only the raw data but also analyses of trends and discussions of their significance. The 1996 edition of the book "World Industrial Robots", to be published later this year, will feature a special chapter on the use of robots in assembly applications. 